\title{
The Ensemble Forecasting Technique of the Thunderstorm
}

\author{
Y.W. Chen \\ Jiangsu Climate Centre, China
}

\begin{abstract}
The convective scale ensemble forecasting is performed by combining the mesoscale non-hydrostatic Weather Research and Forecasting (WRF) model with the Institute ofAtmospheric Physics (IAP) 3-D convective cloud model based on the ensemble weather forecast theory and applied to the forecast of the characteristics of thunderstorms around Nan Jing. The ensemble forecasting of the thunderstorms is verified with the summer Doppler radar data of the thunderstorms in Nan Jing. Results show that the intensity and distribution of thunderstorms over the research area is reasonably predicted one day in advance. It is particularly good to forecast the distribution of the strong thunderstorms with the ensemble forecasting technique. Moreover, the reasonable explanation and application of the convective scale ensemble forecasting is of much importance for the early warning and monitoring of the local thunderstorms and mitigation of the thunder calamity.
\end{abstract}

Keywords-thunderstorm; convective scale; ensemble forecasting;Probability Density Function (PDF);verification

\section{INTRODUCTION}

Against the uncertain of the numerical forecast, Leith suggests the theory of ensemble forecast in 1974. He believe that the weather forecast is not certain forecast, but is the variation of correct PDF of atmosphere in time and space with time, which is transformation from the certain forecast to probability forecast with the feasibility index of certain forecast for increasing the forecast accuracy rate finally. The ensemble forecast is firstly applied in the long and middle forecast. After 1990s Brooks et al.[1] applied the ensemble forecast in mesoscalenumerical forecast. Because the scale of the thunderstorm is small, the ability of the mesoscale ensemble forecast to thunderstorm is limited [2-3]. With the rapid development of the computer technology, if the method of resolving the initial condition of the cloud model is found, the cloud model can be used to forecast the thunderstorm, which is discussed in the paper. The ensemble forecasting technique of the thunderstorm is proposed and applied in forecasting the characteristic of the thunderstorm intensity and distribution around Nan Jing within one day, and then test the forecast effectiveness with the real Doppler radar data.

\section{METHOD OF ENSEMBLE FoRECAST}

The method of ensemble forecast is constructed according the theory of ensemble forecast by mesoscaleunhydrostatic WRF model and 3-dimension convective cloud model researched by the IAP. (Figure I ).

\author{
J. Wang \\ Jiangsu Climate Centre, China
}

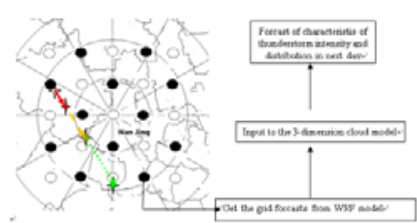

FIGURE I. THE SCHEMATIC DIAGRAM OF ENSEMBLE FORECASTING OF THE CONVECTIVE STORMS . THE RESEARCH AREA IS DIVIDED INTO 21 SMALL AREAS BY THE DASHED LINES AND SITUATED WITHIN THE SECOND CIRCLE. THE DISTANCE BETWEEN TWO ADJACENT CIRCLES (BLACK AND WHITE DOTS) IS 50 (40) KM. THE ASTERISK REPRESENTS THUNDERSTORM LASTING FOR 36 MINUTES DETECTED IN A GIVEN DAY, WHICH WILL REACH THE RED ASTERISK ALONG THE RED LINE AT THE PROBABILITY OF 50\%, THE YELLOW ASTERISK ALONG THE YELLOW LINE AT THE PROBABILITY OF 25 50\%, THE GREEN ASTERISK ALONG THE GREEN LINE AT THE PROBABILITY OF UNDER $25 \%$.

The IAP 3-dimension time variation elastic bracket cloud model divides the water source into five grades of cloud water, rain, ice, grauple and hail, the grauple and hail are divided into 21 grades and the 37 kinds of the detail microphysical process is applicable in the research of the thunderstorm scale characteristics. The domain of the cloud model is $70 \times 70 \times 18.5$ $\mathrm{km}$. The distance in vertical is $0.5 \mathrm{~km}$, and in horizontal is $2 \mathrm{~km}$. The total integrate time is $90 \mathrm{~min}$, and the step of integrate is 10s. The initial disturbance adopts the method of the convective humidity and heat disturbance. The temperature of disturbance is $2.5^{\circ} \mathrm{C}$. The center of disturbance is at the horizontal center at the $3 \mathrm{~km}$. The horizontal radius of the disturbance is $14 \mathrm{~km}$ and vertical radius is $3 \mathrm{~km}$. The initial field is obtained from the results of the new mesoscale hydrostatic WRF model. Because the thunderstorm around Nan Jing within thehorizontal radius of $100 \mathrm{~km}$ is mainly researched in the paper and the thunderstorm in the summer often happened between in the afternoon and at night, extract the next day 06(12h forecast), 09, 12, 15 time forecast results of partial grids within $5 \times 5$ subsidiary domain with the center of Nan Jing. The 12 grid results at every forecast time are extracted. The total 48 initial fields compose the member of the ensemble forecasting of the thunderstorm cloud scale. The results from the 48 time and space discontinuous fields is instead of the thunderstorm characteristics in the total research region and the weight of the 48 forecast results is equal.

The horizontal domain of WRF model is $71 \times 71$ and the distance of the grid is $40 \mathrm{~km}$. The vertical atmosphere is divided into 31 layers. The top pressure of the model is $50 \mathrm{hPa}$. The initial and boundary fields are obtained from the NCEP(National Centers for Environmental Prediction)/NCAR(National Center for Atmospheric 
Research) $1^{\circ} \times 1^{\circ}$ every $6 \mathrm{~h}$ reanalysis data. The start of the integrate is $18 \mathrm{~h}$ every day. The total integrate time is $24 \mathrm{~h}$. The step of the integrate is 60s. The results is output every 3h. Otherwise, the WRF model adopts the Medium Resolution Forecast (MRF) boundary scheme, Kain and Fritsch (KF)convective parameterized scheme, WRF SingleMoment 6-class (WSM6) microphysical process scheme, Rapid radiation Transfer Model (RRTM) long-wave and Dudhia short-wave radiation scheme. The center of the model is identical with the center of Nan Jing Doppler radar.

\section{TEST OF THE EFFECTIVENESS OF THE ENSEMBLE FORECAST}

By now the correct ratio of the trail information StormCellIdentificationandTracking(SCIT) of the thunderstorm by the Doppler radar reaches more than $90 \%$, so the test of the effectiveness of the ensemble forecast adopts 9 days' the Doppler SCIT data in July and August in summer in Nan Jing. For obtain the integral characteristics of the thunderstorm intensity and distribution, the statistical norm of the thunderstorm is as follows: (1) the last time of the thunderstorm must be more than 18mins. (2) The maximum echo reflectivity of the thunderstorm must be greater than 40 $\mathrm{dBZ}$. According to the above norm, do the statistic of the real radar data. The statistic result is that there are 468 thunder storms within 9 days.

\section{A. Forecast of the Thunderstorm Intensity and Test}

The thunderstorm intensity is instead of the lasting time of the thunderstorm. The lasting time of the thunderstorm is decided by the time over the critical norm of the maximum vertical velocity and for being identical with the statistic norm of the real thunderstorm, when the lasting time of the thunderstorm is more than $18 \mathrm{mins}$, records a thunderstorm. Do statistic of the lasting time of the detecting and forecasting thunderstorms in every day, transform the lasting time into non-parameter PDF function, whose distribution is instead of the integral characteristics of total thunderstorms within the region and smooth the function by the method of gauss core density estimate in every $6 \mathrm{mins}$, which is identical with the interval of the Nan Jing Doppler radar. Because the integrate time is $90 \mathrm{mins}$, the range of the independent variable of the PDF is $(0,90)$. When the last time of the detecting thunderstorm is more than $90 \mathrm{mins}$, record the last time as 90mins uniformly. Otherwise, through computing the Euclidean distance (L2 norm) between the forecasted and observed PDFs of the lasting time of the thunderstorm, test the effectiveness of the thunderstorm forecasting of the ensemble forecast. The distance of the Euclidean is smaller, the forecast results is more close to the real data. (Figure II)

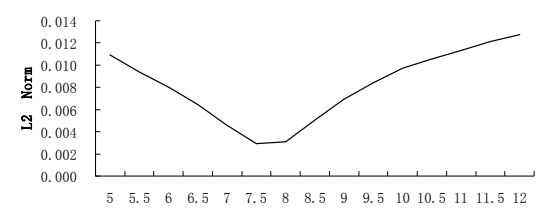

Thresholds of the maximum updraft speed $[\mathrm{m} / \mathrm{s}]$

FIGURE II. THE EUCLIDEAN DISTANCE BETWEEN THE FORECASTED AND OBSERVED PDFS OF THE LASTING TIME OF THE THUNDERSTORM AS A FUNCTION OF THE THRESHOLD FOR THE MAXIMUM UPDRAFT (M/S).

The lasting time of the thunderstorm is decided by the critical norm of the maximum vertical velocity, therefore do the statistic of the PDF of the lasting time of the 9days' thunderstorm as the critical norms between 5 and $12 \mathrm{~m} / \mathrm{s}$ with the interval of $0.5 \mathrm{~m} / \mathrm{s}$ and compute the Euclidean distance between the forecasted and observed PDFs of the lasting time of the thunderstorm as every norm. The analysis shows that the Euclidean distance is smallest as the norm of $7.5 \mathrm{~m} / \mathrm{s}$ and the forecast effectiveness is best. Therefore, 408 thunderstorms are forecasted as the critical norm of $7.5 \mathrm{~m} / \mathrm{s}$.

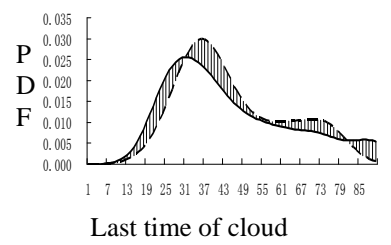

FIGURE III. THE FORECASTED (DASHED) AND OBSERVED (SOLID) PDFS OF THE LASTING TIME OF THE THUNDERSTORM IN ONE DAY WITHIN THE 100KM AROUND NAN JING. THE ORDINATE REPRESENTS THE EUCLIDEAN DISTANCE BETWEEN THE TWO PDFS.

The Figure III shows that both the real and the forecasting by the critical norm of $7.5 \mathrm{~m} / \mathrm{s}$ PDFs of the lasting time of the thunderstorm assume double apexes shape. The forecasting apexes shape is more significant than the real. The extremisms of the real PDF of the lasting time of the thunderstorm are 30mins and 72mins. The thunderstorm whose lifetime reaches $30 \mathrm{mins}$ is most. Whereas the extremisms of the forecasting PDF of the lasting time of the thunderstorm are 36mins and 72mins. Because the forecasting thunderstorm whose lifetime reaches 36mins is most, which make the phase of the forecasting PDF falls behind the phase of the real PDF. Otherwise, the probability forecast of the thunderstorm whose lifetime reaches between $48 \mathrm{mins}$ and $60 \mathrm{mins}$ is identical with the real. The probability forecast of the thunderstorm whose lifetime reaches from $30 \mathrm{mins}$ to $42 \mathrm{mins}$ and from $66 \mathrm{mins}$ to $78 \mathrm{mins}$ is higher than the real. Because the thunderstorm whose lifetime is greater than $90 \mathrm{mins}$ is recorded the thunderstorm whose lifetime is 90mins uniformly in the real statistics, which make the forecasting probability of super thunderstorm is lower than the real. However, if the probability of the thunderstorm whose lifetime is more than 66mins represents the probability of happening severe thunderstorm, the forecast average probability of the severe thunderstorm is identical with the real. 
In summary, the forecast 9 days' distribution of the PDF of the lasting time of the thunderstorm is identical with the real. There are 5 days' forecast results in 9 days' results are close to the real. In the mass, the effectiveness of forecasting the thunderstorm of middle and more intensity within $100 \mathrm{~km}$ around Nan Jing of convective cloud scale ensemble forecast is good.

\section{B. Analysis of the Microphysical Process Forecast of the Thunderstorm Distribution and Test}

The method of forecasting the distribution of thunderstorm within the research region in a day has been shown in Fig.1. As the center of the WRF model nest grid, the region around Nan Jing within $100 \mathrm{~km}$ is divided equally into 21 small regions. If any member of the ensemble forecast forecasts that there is the thunderstorm at the small region, which presents that the thunderstorm will happen at the small region in a day. According to $2 \times 2$ contingency analysis(Table I ), compute the POD (Probability of Detection) and POFD (Probability of False Detection) indexes of the distribution of thunderstorm whose lifetime greater than 30mins, 36mins, 42mins, 48mins, 54mins, 60mins, 66mins and 72mins separately. The ROC (Receiver Operating Characteristic) curve is draw according above POD and POFD indexes and the area below the ROC curve will be computed (the area of bias). The maximum of the area is 1 , instead of the best forecast skill. If the curve overlaps with the broken line, the area is 0.5 , instead of no forecast skill. The real ROC curve is higher than the broken line (Figure IV). The area below the curve is 0.65 , which shows that there is some skill to forecast the distribution of the thunderstorm around Nan Jing, especially better to forecast the distribution of the thunderstorm whose time is greater than 42mins, 48mins and 66mins.

TABLE I . $2 \times 2$ CONTINGENCY ANALYSIS.

\begin{tabular}{|c|c|c|}
\hline \multirow{2}{*}{ Forecasting result } & \multicolumn{2}{|c|}{ Observing result } \\
\cline { 2 - 4 } Thunderstorm & Thunderstorm & No Thunderstorm \\
\hline No thunderstorm & $\mathrm{A}$ & $\mathrm{B}$ \\
\hline & $\mathrm{C}$ & $\mathrm{D}$ \\
\hline
\end{tabular}

FIGURE IV. THE ROC DIAGRAM OF THE THUNDERSTORM DISTRIBUTION FORECAST FOR THE ENSEMBLE FORECAST (THE DOTS ARE THE POD AND POFD OF THE DISTRIBUTION FORECAST OF THUNDERSTORM WHICH REACHED AT LEAST 30, 36, 42, 48, 54, 60, 66, 72 MINUTES FROM THE RIGHT UP AND LEFT DOWN, THE SLASH AREA IS ABOUT 0.65).

\section{CONCLUSION}

The ensemble forecasting technology of thunderstorm is found and applied in forecasting the characteristics of the thunderstorm around Nan Jing by combing the WRF model and 3-dimension convective cloud. Some conclusions are as follows:

(1)The analysis of the difference of the temperature, humidity and wind between 24h forecasting results and the real data, and the K-S (Kolmogorov-Smirnov) distribution test show that the initial fields of the cloud model from the WRF model is creditability.

(2)The effectiveness of forecasting the summer thunderstorm intensity within $100 \mathrm{~km}$ around Nan Jing in a day is well. Especially, the forecasting effectiveness of the occurrence and distribution of the thunderstorm is better than the certain forecast results by WRF model.

\section{ACKNOWLEDGEMENT}

J. Wang is the corresponding author. She makes the great contribution in this research.This research was financially supported by the Jiang Su Meteorology Research Foundation (Grant Nos. Q201516, KM201403, KM201107, Q201205) and the special public welfare industry meteorological research (GYHY201306050).

\section{REFERENCES}

[1] Harold E. Brooks, Charles A. Doswell III, and Louis J. Wicker, STORMTIPE: A Forecasting Experiment Using a Three-Dimensional Cloud Model, Weather Forecasting,American Meteorology Society, 8, 352-362, 1993.

[2] Louis J. Wicker and Robert B. Wilhelmson, Simulation and Analysis of Tornado Development and Decay within a Three-Dimensional Supercell Thunderstorm,Journal of the Atmospheric Sciences, American Meteorology Society, 52, 2675-2703, 1995.

[3] Louis J. Wicker, Michael P. Kay, and Michael P. Foster, STORMTIPE95: Results from a Convective Storm Forecast Experiment, Weather Forecasting, American Meteorology Society, 12, 388-398, 1997. 